\title{
Vertebral column anomalies in Indo-Pacific and Atlantic humpback dolphins Sousa spp.
}

\author{
Caroline R. Weir ${ }^{1,2, *}$, John Y. Wang ${ }^{3,4}$ \\ ${ }^{1}$ Ketos Ecology, 4 Compton Road, Kingsbridge, Devon TQ7 2BP, UK \\ ${ }^{2}$ Department of Zoology, School of Biological Sciences, University of Aberdeen, Tillydrone Avenue, Aberdeen AB24 2TZ, UK \\ ${ }^{3}$ CetAsia Research Group, 310-7250 Yonge Street, Thornhill, Ontario L4J 7X1, Canada \\ ${ }^{4}$ Department of Biology, Trent University, 1600 West Bank Drive, Peterborough, Ontario K9J 7B8, Canada
}

\begin{abstract}
Conspicuous vertebral column abnormalities in humpback dolphins (genus Sousa) were documented for the first time during 3 photo-identification field studies of small populations in Taiwan, Senegal and Angola. Seven Taiwanese humpback dolphins S. chinensis taiwanensis with vertebral column anomalies (lordosis, kyphosis or scoliosis) were identified, along with 2 possible cases of vertebral osteomyelitis. There was evidence from several individuals photographed over consecutive years that the anomalies became more pronounced with age. Three Atlantic humpback dolphins $S$. teuszii were observed with axial deviations of the vertebral column (lordosis and kyphosis). Another possible case was identified in a calf, and 2 further animals were photographed with dorsal indents potentially indicative of anomalies. Vertebral column anomalies of humpback dolphins were predominantly evident in the lumbo-caudal region, but one Atlantic humpback dolphin had an anomaly in the cervico-thoracic region. Lordosis and kyphosis occurred simultaneously in several individuals. Apart from the described anomalies, all dolphins appeared in good health and were not obviously underweight or noticeably compromised in swim speed. This study presents the first descriptions of vertebral column anomalies in the genus Sousa. The causative factors for the anomalies were unknown in every case and are potentially diverse. Whether these anomalies result in reduced fitness of individuals or populations merits attention, as both the Taiwanese and Atlantic humpback dolphin are species of high conservation concern.
\end{abstract}

KEY WORDS: Deformities $\cdot$ Lordosis $\cdot$ Kyphosis $\cdot$ Scoliosis $\cdot$ Sousa chinensis $\cdot$ Sousa teuszii

\section{INTRODUCTION}

Axial and lateral deviations of the vertebral column have been documented from a wide range of species and can be described using the standardised terms presented by Wise et al. (1997): (1) kyphosis: increased convexity in the curvature of the thoracic vertebral column as viewed laterally; (2) lordosis: anterior concavity in the curvature of the lumbar and cervical vertebral column as viewed laterally; and (3) scoliosis: lateral curvature of the vertebral column.

Reports of vertebral column abnormalities in delphinids have included conspicuously deformed individuals observed in situ (e.g. Berghan \& Visser 2000,
Bertulli et al. 2015) and more subtle anomalies revealed during post-mortem examinations (e.g. Kompanje 1995, DeLynn et al. 2011). The causative factors of vertebral column abnormalities in delphinids often remain unclear (Berghan \& Visser 2000) but can include bacterial infections (Kompanje 1995), physical trauma (Watson et al. 2004, Robinson 2014) and congenital disorders (e.g. DeLynn et al. 2011). Most published records relate to bottlenose dolphins Tursiops spp. (e.g. Morton 1978, Alexander et al. 1989, Wilson et al. 1997, Berghan \& Visser 2000, Watson et al. 2004, DeLynn et al. 2011, Robinson 2014), although it is unclear whether this is due to higher incidences of abnormalities in Tursiops or whether it 
is simply an artefact of greater research attention afforded to this genus worldwide. Published records describe vertebral abnormalities in several other delphinids, including killer whale Orcinus orca (Berghan \& Visser 2000), Risso's dolphin Grampus griseus (Nutman \& Kirk 1988), white-beaked dolphin Lagenorhynchus albirostris (Bertulli et al. 2015), common dolphin Delphinus spp. (Berghan \& Visser 2000, Van Bressem et al. 2006) and Hector's dolphin Cephalorhynchus hectorii (Berghan \& Visser 2000).

There are currently no published accounts of vertebral column abnormalities in humpback dolphins (genus Sousa), which comprise the Atlantic humpback dolphin $S$. teuszii, the Indian Ocean humpback dolphin S. plumbea, the Indo-Pacific humpback dolphin $S$. chinensis and the Australian humpback dolphin S. sahulensis (Jefferson \& Rosenbaum 2014). Humpback dolphins are distributed across shallow, coastal tropical and subtropical waters from the African Atlantic, east throughout the Indian Ocean, to Asia and the western Pacific (Jefferson \& Rosenbaum 2014), a geographic area with a high diversity of anthropogenic threats and often limited resources for cetacean research.

This paper provides the first descriptions of vertebral column anomalies photographed in free-ranging dolphins from 2 species of the genus Sousa. The Taiwanese humpback dolphin S. chinensis taiwanensis was recently described as a distinct subspecies and is endemic to the inshore shallow waters off western Taiwan (Wang et al. 2015). The subspecies comprises fewer than 75 individuals (Wang et al. 2012) and is listed as Critically Endangered on the IUCN Red List of Threatened Species because it is a small population that faces many threats and is projected to be declining (Reeves et al. 2008). The Atlantic humpback dolphin is endemic to shallow inshore Atlantic African waters from the Western Sahara to Angola (Weir et al. 2011). It is listed as Vulnerable on the IUCN Red List (although its status is currently under review) due to suspected low global population size, susceptibility to threats and an inferred or suspected continuing decline in numbers (Weir et al. 2011).

\section{MATERIALS AND METHODS}

Photographic data documenting vertebral anomalies in 2 Sousa species were recorded during 3 independent field studies in Taiwan, Angola and Senegal. A long-term photo-identification study of the Taiwanese humpback dolphins has been carried out since 2007 (see Wang et al. 2012). A $4.5 \mathrm{~m}$ boat was used to survey a series of predetermined transects along approximately $200 \mathrm{~km}$ of coastal waters off central western Taiwan (the study area has been extended since Wang et al. 2012). Dolphins were photographed using digital SLR cameras fitted with $80-200,300$ or $100-400 \mathrm{~mm}$ lenses.

An Atlantic humpback dolphin study was carried out off Flamingos $\left(15^{\circ} 33^{\prime} \mathrm{S}, 12^{\circ} 01^{\prime} \mathrm{E}\right)$ in southern Angola over 2 field seasons in January and June/July 2008 using combined boat-, fixed-shore and vehiclebased methodologies (see Weir 2009). Another study was carried out in the Saloum Delta (central position at $13^{\circ} 50^{\prime} \mathrm{N}, 16^{\circ} 40^{\prime} \mathrm{W}$ ), Senegal, during October and November 2015 (see Weir in press). Both surveys used small boats $(<6 \mathrm{~m})$ to document the spatial distribution and minimum number of dolphins present in the area. Non-systematic photography of dolphins was carried out using a digital SLR camera and a 100-400 mm lens.

Individuals with markings suitable for identification were catalogued according to the methods of Würsig \& Jefferson (1990). For the Taiwanese humpback dolphins, the primary marks for individual identification were unique spotting patterns, which are diagnostic characters that are consistent over time (see Wang et al. 2012). For Atlantic humpback dolphins, individual identification was based on the pattern of nicks in the trailing edge of the dorsal fin (permanent marks) and scar patterns on the fin and body (temporary marks) (Weir 2009, in press). Individuals were assigned to 1 of 3 age categories based on their size relative to other animals in the group (Parra et al. 2006): (1) adults, approximately 2-3 m long; (2) juveniles, approximately two-thirds the length of an adult, sometimes associated with an adult but often swimming independently; and (3) calves, less than two-thirds the length of an adult, and in close association with an adult.

During both fieldwork and subsequent photo-identification and cataloguing of photographs, individuals with conspicuous vertebral anomalies were noted opportunistically by the authors. The anomalies are described below using the terminology adopted by Bertulli et al. (2015) for delphinids.

\section{RESULTS}

The full catalogue of individual Taiwanese humpback dolphins consists of more than 95 individuals, but only 71 of those have been observed in the past 5 yr (Wang et al. 2012). Ten individual Atlantic hump- 
back dolphins were photo-identified off southern Angola (Weir 2009), while a total of 103 individuals were identified in the Saloum Delta (Weir in press). A summary of the individuals with vertebral anomalies in the 2 Sousa species is presented in Table 1.

\section{Taiwanese humpback dolphin}

Seven Taiwanese humpback dolphins were observed with vertebral column anomalies (lordosis, kyphosis or scoliosis), and an additional individual appeared to have possible osteomyelitis in the caudal vertebrae.

The most severe anomaly seen in a Taiwanese humpback dolphin was a presumed adult male (TW50) which had concavity followed by convexity in the lumbo-caudal region (Fig. 1a,b). The appearance was consistent with both lordosis and kyphosis. This individual was also heavily scarred with tooth rakes, the tips of the dorsal fin and tail flukes were heavily worn, and it had numerous nicks and scars along the lumbo-caudal region.

A juvenile (TW-98; independent of the mother) had mild concavity and convexity in the caudal region, consistent with lordosis and kyphosis (Fig. 1c). The condition appears to have become more pronounced with age as demonstrated by the increased concavity between 2010, when it was not noticeable (Fig. 1d), and 2013 (Fig. 1e). Scoliosis was evident as lateral concavity on the right side (Fig. 1c). TW-98 was also heavily scarred with tooth rakes (almost certainly due to conspecifics).
Individual TW-108 was a dependent calf that did not show signs of any vertebral anomalies when photographed in 2010 (Fig. 1f). However, this animal showed a slight lordotic curvature in the dorsal ridge of the caudal region by 2013 (Fig. 1g). Additionally, since 2011, a swelling located lateral to the caudal vertebra was apparent on the left side, which is a possible sign of osteomyelitis (Fig. 1h).

A dependent (when seen from 2007 to 2014) calf, TW-100, exhibited a prominent swelling in the caudal region on the right peduncle, potentially indicating osteomyelitis (Fig. 1i). Immediately below the enlargement was a large hyper-pigmented area on the skin. This calf was also observed with a fishing line wrapped around its torso in 2012 and 2013 but had lost the line when photographed in 2014; fortunately, the line did not appear to result in injury, at least to its dorsal surface.

Scoliosis was photographed in 4 individuals (TW04, TW-17, TW-87 and TW-103; Fig. 1j-m). In all cases, scoliosis was evident in the lumbo-caudal region immediately posterior to the dorsal fin.

\section{Atlantic humpback dolphin}

The diagnosis of vertebral column anomalies in Atlantic humpback dolphins was complicated by the extreme morphology of this species (see Fig. S1 in the Supplement, available at www.int-res.com/ articles/suppl/d120p179_supp.pdf). Three Atlantic humpback dolphins were identified with vertebral column anomalies. An additional possible case was

Table 1. Photographic records (by date) of vertebral column anomalies in Sousa chinensis (SC) and S. teuszii (St). A photographic 'capture' is defined here as a single record of an individual per day (i.e. omitting re-captures on the same day). TW: Taiwan; SD: Saloum Delta, Senegal; FL: Flamingos, Angola. A: adult; J: juvenile; C: calf

\begin{tabular}{|c|c|c|c|c|c|c|c|}
\hline Ref. & Species & ID code & \multicolumn{2}{|c|}{ Date of capture (dd/mm/yy) } & $\begin{array}{c}\text { Total } \\
\text { captures }\end{array}$ & Age & Type of malformation \\
\hline 1 & SC & TW-04 & $24 / 06 / 02$ & $30 / 06 / 14$ & 10 & A & Scoliosis \\
\hline 2 & $S C$ & TW-17 & 02/04/03 & $28 / 07 / 14$ & 14 & A & Scoliosis \\
\hline 3 & $S C$ & TW-50 & 04/07/07 & $28 / 07 / 14$ & 31 & A & Lordosis and kyphosis \\
\hline 4 & $S C$ & TW-87 & 05/08/08 & $20 / 06 / 15$ & 31 & A & Scoliosis \\
\hline 5 & $S C$ & TW-98 & 05/08/08 & 16/07/14 & 33 & $\mathrm{~J}$ & Scoliosis, mild lordosis and kyphosis \\
\hline 6 & SC & TW-100 & $31 / 08 / 08$ & $27 / 06 / 14$ & 10 & $\mathrm{C}$ & Possible osteomyelitis? \\
\hline 7 & $S C$ & TW-103 & $12 / 04 / 10$ & 04/07/15 & 15 & A & Scoliosis \\
\hline 8 & $S C$ & TW-108 & $14 / 07 / 10$ & $22 / 06 / 15$ & 28 & $\mathrm{C}$ & Osteomyelitis and mild lordosis \\
\hline 9 & St & FL5 & $12 / 01 / 08$ & 05/07/08 & 20 & A & Lordosis and kyphosis \\
\hline 10 & $S t$ & SD_P34 & $30 / 10 / 15$ & 05/11/15 & 3 & A & Lordosis and kyphosis \\
\hline 11 & St & SD_P11 & $26 / 10 / 15$ & 29/10/15 & 3 & A & Lordosis and kyphosis \\
\hline 12 & St & SD_U8 & $06 / 11 / 15$ & 06/11/15 & 1 & $\mathrm{C}$ & Possible lordosis and kyphosis? \\
\hline 13 & St & SD_P8 & $24 / 10 / 15$ & $06 / 11 / 15$ & 4 & $\mathrm{~J}$ & Vertebral indent \\
\hline 14 & St & SD_P51 & $27 / 10 / 15$ & 06/11/15 & 3 & A & Vertebral indents \\
\hline
\end{tabular}



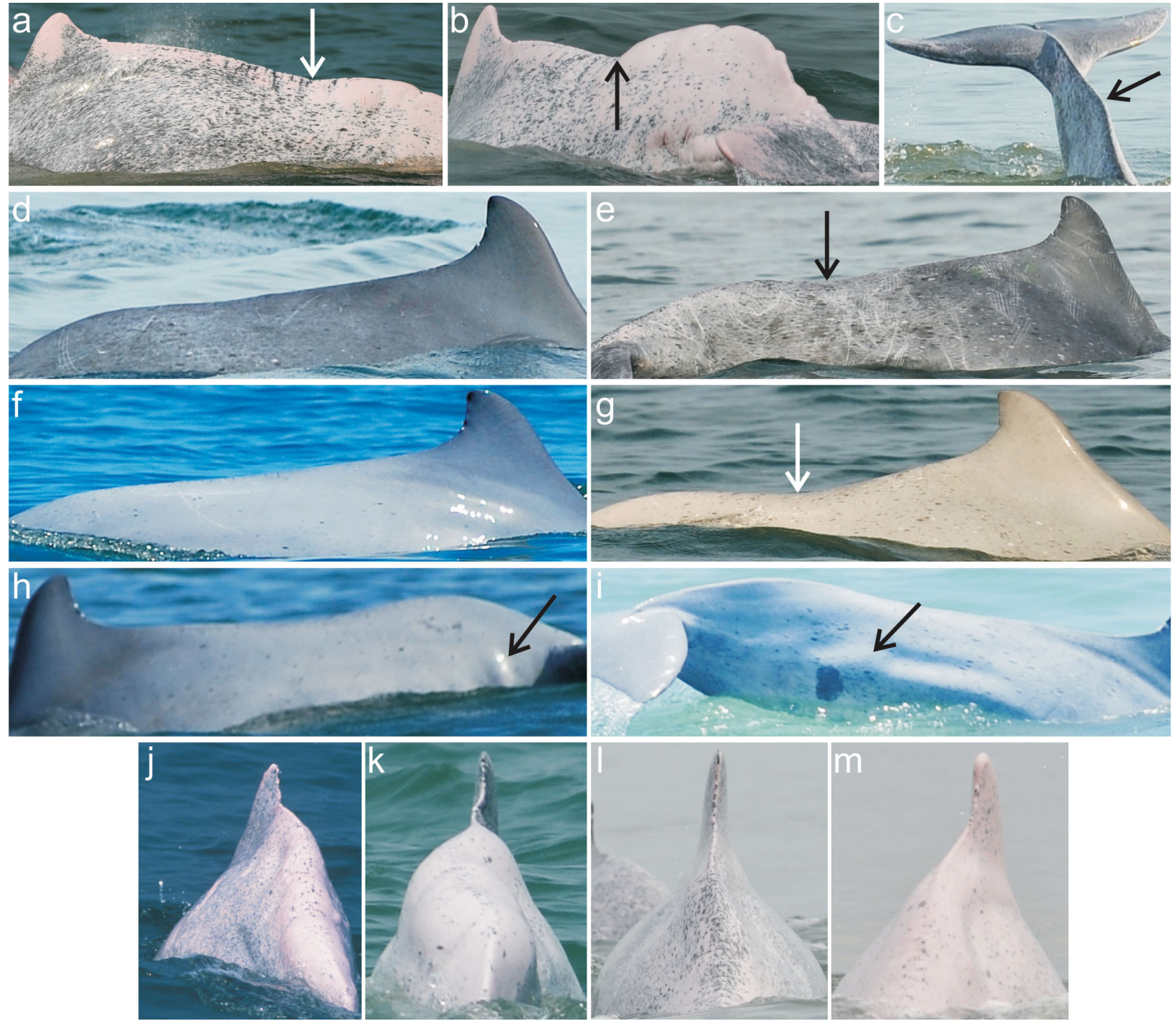

Fig. 1. Vertebral column anomalies photographed in Sousa chinensis. Combined lordosis and kyphosis recorded in (a) TW-50 (2008), (b) TW-50 (2014), (c) TW-98 (2014), (d) TW-98 (2010) and (e) TW-98 (2013). Development of lordosis in TW-108 (f) 2010 compared with (g) 2013. Possible osteomyelitis of the caudal vertebrae in (h) TW-108 (2011) and (i) TW-100 (2012). Scoliosis in (j) TW-04, (k) TW-17, (l) TW-87 and (m) TW-103. Arrow points to (a,b,e) lordosis, (c) scoliosis, (g) mild lordosis, (h) swelling lateral to the caudal vertebra, (i) swelling in the caudal region on the right peduncle. Photographs: $(a, d, f, h, i, j)$ by J. Y. Wang/ FormosaCetus Research and Conservation Group; (c,e,g) by J. Y. Wang/CetAsia Research Group; (b,k) by C. AraújoWang/CetAsia Research Group; $(1, \mathrm{~m})$ by J. M. Hoffman/CetAsia Research Group

documented in a calf, and 2 further animals had dorsal indents potentially indicative of anomalies.

The most severe anomaly recorded was individual SD_P34, an adult exhibiting both lordosis and kyphosis that were apparent as significant concavity and convexity in the caudal region (Fig. 2a,b). SD_P34 had additional markings deemed unusual by comparison with other Atlantic humpback dolphins photographed during the Senegal fieldwork and similar studies off Angola (Weir 2009) and Guinea (Weir
2015): (1) the top of the dorsal fin was severed (also observed in a small number of other individuals at the 3 sites); (2) the leading edge of the upper dorsal fin was severed; (3) there was unusual raised scarring (healed) around the edges of the dorsal hump and fin; (4) there was extensive raised linear scarring (healed) on the tailstock; and (5) there was an unusually high amount of damage to the trailing edges of the tail flukes (both tips missing and a series of large notches). 

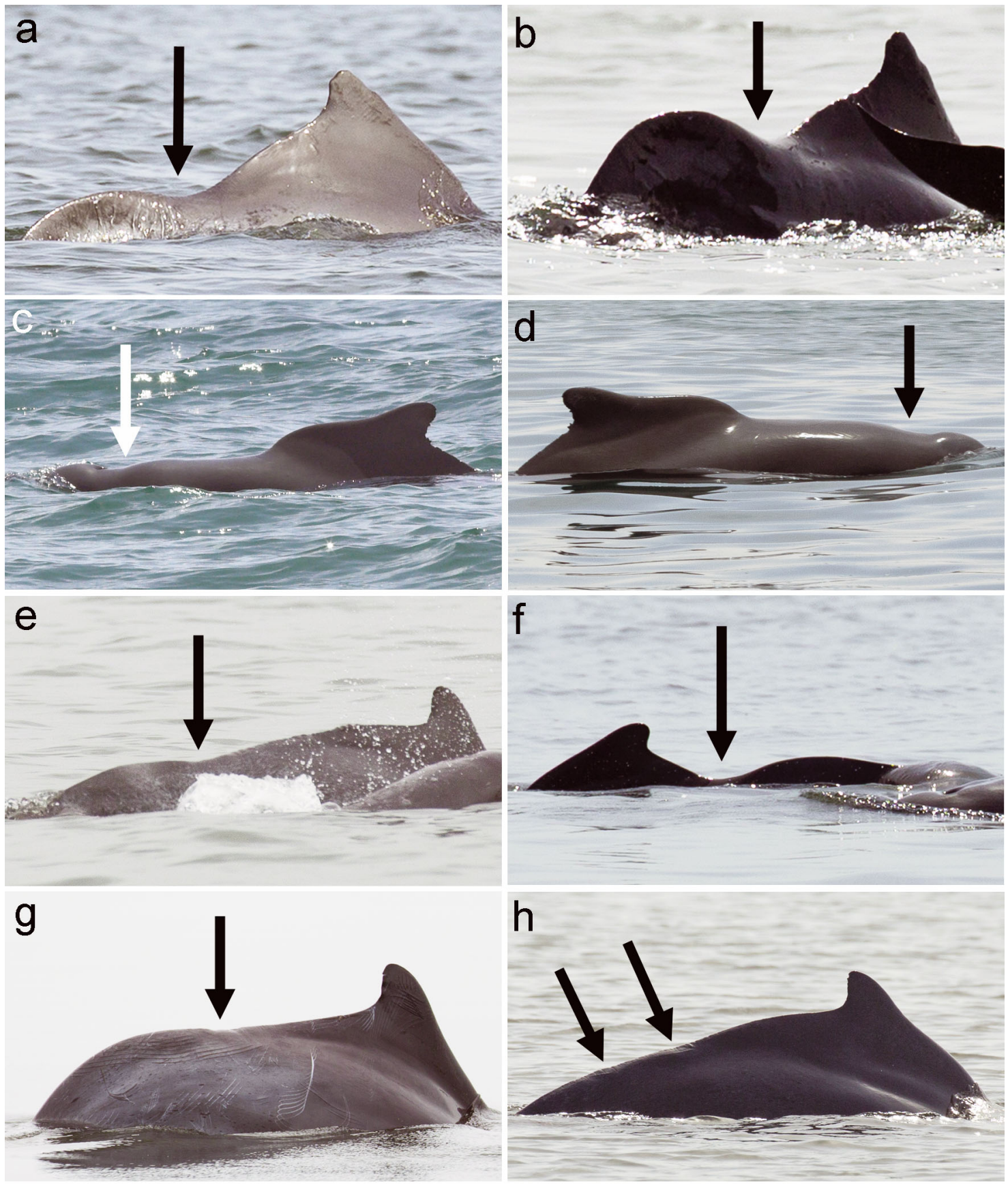

Fig. 2. Vertebral column anomalies photographed in Sousa teuszii. Combined lordosis and kyphosis (with lordosis indicated by arrow) recorded in: (a,b) SD_P34, (c,d) FL5, (e) SD_P11 and (f) possible case in the neonate SD_U8. Vertebral indents (positions shown by arrows) recorded in: (g) SD_P8 and (h) SD_P51. Photos: C.R. Weir

An adult (FL5) photographed repeatedly off southern Angola during 2008 had a marked depression around, and posterior to, the blowhole. Just posterior to this depression a convex bulge was present, resulting in an unusually 'lumpy' dorsal profile (Fig. 2c,d). These symptoms were consistent with slight lordosis and kyphosis in the cervico-thoracic region.
An anomaly was present in SD_P11, a heavilyscarred adult that had a series of distinctive raised 'knuckle'-like scars extending dorsally from the trailing edge of the dorsal hump into the caudal region. Just posterior to the 'knuckles' was an area of concavity followed by convexity, consistent with lordosis and kyphosis (Fig. 2e). 
Another potential case of lordosis and kyphosis was suggested by strong concavity and convexity photographed in the lumbo-caudal region of a neonate calf (SD_U8; Fig. 2f). This individual was photographed during a single encounter, and only one clear image of the tailstock was obtained. Consequently, the case is unconfirmed.

Two other individuals exhibited shallow indents along their dorsal ridges that were considered potentially indicative of anomalies. SD_P8 was a juvenile that had a conspicuous shallow indent dorsally, located immediately posterior to where the trailing edge of the dorsal hump merged with the tailstock (Fig. 2g). SD_P51 was an adult that had 2 shallow indents along the dorsal ridge, the first immediately posterior to the confluence between the trailing edge of the dorsal hump and the tailstock, and the second in the lumbo-caudal region (Fig. 2h).

\section{DISCUSSION}

This study presents the first descriptions of vertebral column anomalies in the genus Sousa. The deviations in vertebral column curvature described here for Taiwanese and Atlantic humpback dolphins are consistent with documented abnormalities in other delphinids, termed lordosis, kyphosis and scoliosis by Bertulli et al. (2015). While only one of these conditions was apparent in most animals, lordosis and kyphosis occurred simultaneously in several individuals. These abnormalities have also occurred in combination in some other delphinids, for example in white-beaked dolphins in Iceland (Bertulli et al. 2015).

The Atlantic humpback dolphin has received very little research focus to date, and no previously published accounts of abnormalities or disease are available. By comparison, the Indo-Pacific humpback dolphin is relatively well-studied, and there are published reports of disease such as bacterial infections (Parsons \& Jefferson 2000), parasites (Parsons et al. 2001) and epidermal conditions (Yang et al. 2013). In addition, overt physical disfigurement (e.g. deep grooves in the tailstock, propeller gashes or amputated dorsal fins) associated with vessel collisions or interactions with fishing gear have also been documented in Atlantic humpback dolphins (Weir 2015), and especially in Indo-Pacific humpback dolphins (e.g. Parsons \& Jefferson 2000, Slooten et al. 2013). The examples of vertebral column anomalies described here add to the available literature on the injuries affecting Sousa species.
It should be emphasised that none of the Sousa field studies focussed specifically on documenting vertebral column malformations, and consequently the data presented here do not represent a systematic account of occurrence in these regions but rather are ad hoc examples. It is likely that other examples exist, because photo-identification work focusses on obtaining perpendicular images of the dorsal fin area rather than other parts of the body. Photographing from different angles might be advantageous for identifying instances of scoliosis or other vertebral column anomalies.

An additional challenge for identifying anomalies in the Atlantic humpback dolphin, compared with the Indo-Pacific humpback dolphin and other delphinids, is the complex morphology of the dorsal hump and upper flank areas of the former species, especially in those individuals with very prominent humps, keels and associated areas of lateral musculature which produce a variable 'lumpy' appearance. The presence of concavity between the hump and the keel was first noted in the Indian Ocean humpback dolphin by Fraser (1966), and the degree to which this concavity was evident in Atlantic humpback dolphins depended on variation in both the prominence of the morphological traits and in the flexion of the tailstock according to speed and angle during surfacing behaviour (see Fig. S1). Consequently, it was problematic to conclusively identify abnormalities (especially lordosis) in the tailstock of Atlantic humpback dolphins, and there were additional possible cases of anomalies from all field studies that could not be confirmed.

The majority of published records of vertebral column abnormalities show a bias towards rather severe cases such as individuals SD_P34 and TW-50 described here (e.g. Berghan \& Visser 2000, Robinson 2014, Bertulli et al. 2015), because identification of mild lordosis may be difficult to ascertain in most cetacean species. Although vertebral column abnormalities span the entire range from those where animals appear relatively normal externally (e.g. DeLynn et al. 2011) to the highly conspicuous examples above, there has been little documentation of subtle cases such as a killer whale with slight lordosis in New Zealand (Case No. 7; Berghan \& Visser 2000) and a white-beaked dolphin with mild lordosis and kyphosis in Iceland (Case 5; Bertulli et al. 2015). The latter examples are not dissimilar to the normal concavity and keel evident in the tailstock of many Atlantic humpback dolphins (e.g. Fig. S1b), so mild cases of lordosis in different cetacean species may be difficult to diagnose and thus easily overlooked. Fur- 
ther studies of normal and abnormal specimens through post-mortem examinations, especially of individuals that have been monitored in the field, would help to clarify the incidence and severity of vertebral column anomalies.

Mobility is fundamental to the ability of a dolphin to interact with conspecifics, capture prey and avoid predation. The main propulsive force is generated by vertical oscillation of the caudal peduncle and flukes (Viglino et al. 2014). Consequently, abnormalities in the vertebral column might compromise the mobility of a dolphin, with implications for potentially reducing survivorship and lifetime reproductive success. Despite this, the behaviour of the Sousa individuals described here was not notably different from that of the other individuals with which they were associated, and there were no indications that these individuals were compromised relative to their conspecifics. Apart from the described anomalies, all dolphins appeared in good health and were not obviously underweight, except possibly TW-108. That individual had a large indentation (concavity) beneath the dorsal fin on its left side, which may indicate additional problems with the thoracic vertebrae or poor body condition. Although there was no evidence of obvious compromise when observed at the surface, individuals with anomalies might experience reduced fitness if, for example, they were unable to compete as effectively for mates, afflicted calves depended on their mothers for longer periods, or lifespan was reduced compared to those without such abnormalities.

The longevity of delphinids with vertebral column abnormalities depends on factors including the type, location and extent of the original malformation, changes as the animal grows and resulting pathological complications (Berghan \& Visser 2000, DeLynn et al. 2011). Consequently, the effects may range from asymptomatic to severe distortion (DeLynn et al. 2011). At least some individuals survive into adulthood (e.g. Wilson et al. 1997, DeLynn et al. 2011), while the premature mortality of others may occur as a direct result of their vertebral injuries (e.g. Watson et al. 2004, Robinson 2014). There appears to be some indication from the Taiwanese humpback dolphin study that the severity of abnormalities in the vertebral column can become more pronounced with age. However, more data from long-term monitoring of such afflicted individuals are needed to better understand how such vertebral abnormalities are manifested, and how animals may be compromised. None of the Atlantic humpback dolphin field studies have been of sufficient longevity to determine whether vertebral anomalies affect survivorship.
The causal factors of the vertebral column malformations described here for the genus Sousa were unknown in every case and are potentially diverse. It is possible that some are congenital anomalies with defects arising in the developing foetus as a result of genetic or environmental factors (e.g. DeLynn et al. 2011). The small population sizes at all of the study sites considered here may increase the likelihood of congenital anomalies due to low genetic diversity within the few reproductive individuals that exist. In contrast, in the largest and best studied population of humpback dolphins in the world (i.e. Indo-Pacific humpback dolphins in the Pearl River Estuary), the types of vertebral column anomalies reported here have not been observed (J. Y. Wang unpubl. data, S. K. Hung pers. comm.). Similarly, no anomalies have been noted during studies of the wide-ranging Indian Ocean humpback dolphins from the south (Plett to Gansbaai; B. James pers. comm.) or east (St. Francis Bay to Port Edward; S. Plön pers. comm.) coasts of South Africa. Combined 'populations' comprising several hundred animals inhabit that area (Braulik et al. 2015), and there is evidence from Richards Bay that Sousa populations in this region are open in nature and comprise part of a larger biological population, potentially exhibiting spatial movements of several hundred kilometres (Keith et al. 2002). Consequently, genetic diversity may be higher in both the Pearl River and South African waters than in the small populations considered in this study.

Such anomalies may also be caused by physical trauma, either of anthropogenic nature (e.g. vessel strike or interaction with fishing gear) or originating from agonistic physical interactions with other delphinids (e.g. Watson et al. 2004, Robinson 2014). The unusual array of additional markings observed on SD_P34 could perhaps be indicative of some type of physical trauma (e.g. vessel strike or interaction with fishing gear). However, the abnormality could also be developmental, since more soft tissue damage would be expected following a physical trauma of sufficient scale to cause such a marked malformation (N. Davison pers. comm.). The unusual raised scarring around the hump, fin and caudal peduncle in SD_P34 could potentially originate from tooth rake scars exacerbated by infection; linear scars of this appearance have also been seen in the Taiwanese humpback dolphin where they are almost certainly caused by conspecifics. There were similarities in the pronounced vertebral column anomaly and scarring of SD-P34 and TW-50. The latter individual was observed in several physical altercations with other 
presumed males which resulted in a high level of scarring and nicks, and may also potentially represent the origin of its vertebral column anomaly.

The 'knuckle' type markings evident on the dorsal ridges of SD_P11 may be similar to the 'cobblestone' skin lesions documented on the dorsal and ventral ridges of the caudal peduncle and on the pectoral fins of botos Inia geoffrensis (Martin \& da Silva 2006). The cause is unknown but may be scar tissue from old wounds or a male-specific developmental thickening of the skin in areas of the body that are targeted during conflict with other males.

Almost all of the instances of vertebral column anomalies reported here in the genus Sousa related to the lumbo-caudal region. However, there was one example of an Atlantic humpback dolphin (FL5) where an anomaly was apparent in the cervico-thoracic region. This appears to be similar in nature to case no. 8 described by Berghan \& Visser (2000), comprising an adult killer whale with slight kyphosis in the cervico-thoracic region and a noticeable depression directly at the blowhole. Possible explanations for this bias include a higher likelihood of fatality for anomalies in the cervico-thoracic region compared with the caudal region, or a higher incidence in the caudal region due to that area being more exposed to boat strikes (e.g. when diving away from a boat) or conspecific injury (e.g. when being chased by other animals during antagonistic or social interactions).

This paper indicates that a variety of vertebral column anomalies can occur in the genus Sousa. The future collection of images from different angles may prove useful for monitoring the conditions of these animals and may reveal additional examples. Systematic evaluations are needed before any conclusions can be drawn regarding the true incidence of these abnormalities in the populations considered here and elsewhere. Whether the anomalies result in reduced fitness of the individuals or populations involved also merits attention, since both the Taiwanese and the Atlantic humpback dolphin are species of high conservation concern. Long-term monitoring programmes and the necropsy of dead animals will be required to clarify these issues.

Acknowledgements. Financial support for the field work that resulted in the Taiwanese humpback dolphin photographs analysed in this study was provided primarily by CetAsia Research Group, the Voluntary Fund for Small Cetacean Conservation Research (International Whaling Commission), Wild At Heart Legal Defense Association, FormosaCetus Research and Conservation Group, Hong Kong Cetacean Research Project, Hong Kong Dolphin Conserva- tion Society and Ocean Park Conservation Foundation, Hong Kong. We thank C. Araújo-Wang and J. M. Hoffman for their photographic contributions. The Atlantic humpback dolphin fieldwork in Senegal was sponsored and supported by Sylvatrop, the Direction des Parcs Nationaux and the Direction des Aires Marines Communautaire Protégées. The hotel Keur Saloum at Toubacouta kindly provided some accommodation. Thanks to Maurice Faye, El Hadji Malick Dia and Jean-Sébastien Fauchet for their assistance during the Senegal fieldwork. The Angola fieldwork received financial support from Ketos Ecology, the Whale and Dolphin Conservation Society, and the University of Aberdeen (UK) Small Grants Fund.

\section{LITERATURE CITED}

Alexander JW, Solangi MA, Riegel LS (1989) Vertebral osteomyelitis and suspected diskospondylitis in an Atlantic bottlenose dolphin (Tursiops truncatus). J Wildl Dis 25:118-121

Berghan J, Visser IN (2000) Vertebral column malformations in New Zealand delphinids with a review of cases world wide. Aquat Mamm 26:17-25

Bertulli CG, Galatius A, Kinze CC, Rasmussen MH and others (2015) Vertebral column deformities in white-beaked dolphins from the eastern North Atlantic. Dis Aquat Org 116:59-67

Braulik GT, Findlay K, Cerchio S, Baldwin R (2015) Assessment of the conservation status of the Indian Ocean humpback dolphin (Sousa plumbea) using the IUCN Red List criteria. Adv Mar Biol 72:119-141

> DeLynn R, Lovewell G, Wells RS, Early G (2011) Congenital scoliosis of a bottlenose dolphin. J Wildl Dis 47:979-983

Fraser FC (1966) Comments on the Delphinoidea. In: Norris KS (ed) Whales, dolphins and porpoises. University of California Press, Berkeley, CA, p 7-31

Jefferson TA, Rosenbaum HC (2014) Taxonomic revision of the humpback dolphins (Sousa spp.), and description of a new species from Australia. Mar Mamm Sci 30: 1494-1541

Keith M, Peddemors VM, Bester MN, Ferguson JWH (2002) Population characteristics of Indo-Pacific humpback dolphins at Richards Bay, South Africa: implications for incidental capture in shark nets. S Afr J Wildl Res 32: 153-162

Kompanje EJO (1995) On the occurrence of spondylosis deformans in white-beaked dolphins Lagenorhynchus albirostris (Gray, 1846) stranded on the Dutch coast. Zool Meded (Leiden) 69:231-250

Martin AR, da Silva VMF (2006) Sexual dimorphism and body scarring in the boto (Amazon river dolphin) Inia geoffrensis. Mar Mamm Sci 22:25-33

Morton B (1978) Osteomyelitis (pyogenic spondylitis) of the spine in a dolphin. J Am Vet Med Assoc 173:1119-1120

Nutman AW, Kirk EJ (1988) Abnormalities in the axial skeleton of a Risso's dolphin, Grampus griseus. NZ Vet J 36: 91-92

Parra GJ, Corkeron PJ, Marsh H (2006) Population sizes, site fidelity and residence patterns of Australian snubfin and Indo-Pacific humpback dolphins: implications for conservation. Biol Conserv 129:167-180

> Parsons ECM, Jefferson TA (2000) Post-mortem investigations on stranded dolphins and porpoises from Hong Kong waters. J Wildl Dis 36:342-356 
Parsons ECM, Overstreet RM, Jefferson TA (2001) Parasites from Indo-Pacific hump-backed dolphins (Sousa chinensis) and finless porpoises (Neophocaena phocaenoides) stranded in Hong Kong. Vet Rec 148:776-780

Reeves RR, Dalebout ML, Jefferson TA, Karczmarski L and others (2008) Sousa chinensis (Eastern Taiwan Strait subpopulation). The IUCN Red List of Threatened Species 2008. Available at http://www.iucnredlist.org/details/ 133710/0 (accessed on 6 February 2016) doi:10.2305/ IUCN.UK.2008.RLTS.T133710A3873928.en

Robinson KP (2014) Agonistic intraspecific behavior in freeranging bottlenose dolphins: calf-directed aggression and infanticidal tendencies by adult males. Mar Mamm Sci 30:381-388

Slooten E, Wang JY, Dungan SZ, Forney KA and others (2013) Impacts of fisheries on the Critically Endangered humpback dolphin Sousa chinensis population in the eastern Taiwan Strait. Endang Species Res 22:99-114

- Van Bressem MF, Van Waerebeek K, Montes D, Kennedy S and others (2006) Diseases, lesions and malformations in the long-beaked common dolphin Delphinus capensis from the Southeast Pacific. Dis Aquat Org 68:149-165

Viglino M, Flores DA, Ercoli MD, Álvarez A (2014) Patterns of morphological variation of the vertebral column in dolphins. J Zool (Lond) 294:267-277

Wang JY, Yang SC, Fruet PF, Secchi ER (2012) Mark-recapture analyses of the critically endangered eastern Taiwan Strait population of Indo-Pacific humpback dolphins (Sousa chinensis): implications for conservation. Bull Mar Sci 88:885-902

Wang JY, Yang SC, Hung SK (2015) Diagnosability and description of a new subspecies of Indo-Pacific humpback dolphin, Sousa chinensis (Osbeck, 1765), from the

Editorial responsibility: Steven Raverty, Abbotsford, British Columbia, Canada
Taiwan Strait. Zool Stud 54:36 doi:10.1186/s40555-0150115-x

Watson A, Bahr RJ, Alexander JW (2004) Thoracolumbar kyphoscoliosis and compression fracture of a thoracic vertebra in a captive bottlenose dolphin (Tursiops truncatus). Aquat Mamm 30:275-278

> Weir CR (2009) Distribution, behaviour and photo-identification of Atlantic humpback dolphins Sousa teuszii off Flamingos, Angola. Afr J Mar Sci 31:319-331

$>$ Weir CR (2015) Photo-identification and habitat use of Atlantic humpback dolphins Sousa teuszii around the Río Nuñez Estuary in Guinea, West Africa. Afr J Mar Sci 37:325-334

Weir CR (in press) Atlantic humpback dolphins (Sousa teuszii) in the Saloum Delta (Senegal): distribution, relative abundance and photo-identification. Afr J Mar Sci

Weir CR, Van Waerebeek K, Jefferson TA, Collins T (2011) West Africa's Atlantic humpback dolphin (Sousa teuszii): endemic, enigmatic and soon Endangered? Afr Zool 46: $1-17$

Wilson B, Thompson PM, Hammond PS (1997) Skin lesions and physical deformities in bottlenose dolphins in the Moray Firth: population prevalence and age-sex differences. Ambio 26:243-247

> Wise LD, Beck SL, Beltrame D, Beyer BK and others (1997) Terminology of developmental abnormalities in common laboratory mammals (version 1). Teratology 55:249-292

Würsig B, Jefferson TA (1990) Methods of photo-identification for small cetaceans. Rep Int Whaling Comm 12:43-52

Yang WC, Chang WL, Kwong KH, Yao YT, Chou LS (2013) Prevalence of epidermal conditions in critically endangered Indo-Pacific humpback dolphins (Sousa chinensis) from the waters of Western Taiwan. Pak Vet J 33:505-509

Submitted: February 18, 2016; Accepted: May 29, 2016 Proofs received from author(s): June 25, 2016 